\title{
Nathalie Mauriac Dyer, Proust inachevé. Le dossier «Albertine disparue»
}

\section{Emanuele Kanceff}

\section{Q OpenEdition}

1 Journals

\section{Edizione digitale}

URL: http://journals.openedition.org/studifrancesi/33582

DOI: 10.4000/studifrancesi.33582

ISSN: 2421-5856

\section{Editore}

Rosenberg \& Sellier

\section{Edizione cartacea}

Data di pubblicazione: 1 décembre 2005

Paginazione: 673

ISSN: 0039-2944

\section{Notizia bibliografica digitale}

Emanuele Kanceff, «Nathalie Mauriac Dyer, Proust inachevé. Le dossier «Albertine disparue»», Studi Francesi [Online], 147 (XLX | III) | 2005, online dal 30 novembre 2015, consultato il 18 avril 2021. URL: http://journals.openedition.org/studifrancesi/33582 ; DOI: https://doi.org/10.4000/studifrancesi. 33582

Questo documento è stato generato automaticamente il 18 avril 2021.

\section{(c) (1)}

Studi Francesi è distribuita con Licenza Creative Commons Attribuzione - Non commerciale - Non opere derivate 4.0 Internazionale. 


\title{
Nathalie Mauriac Dyer, Proust inachevé. Le dossier «Albertine disparue»
}

\author{
Emanuele Kanceff
}

\section{NOTIZIA}

NATHALIE MAURIAC DYER, Proust inachevé. Le dossier «Albertine disparue», Paris, Honoré Champion Éditeur, 2005 («Recherches proustiennes», 6), pp. 405.

1 Nel 1987 l'A. pubblicava il testo di un dattiloscritto corretto da Marcel Proust nell'anno stesso della sua morte, il 1922. Si trattava di un documento ignorato a lungo e mai utilizzato a fini di pubblicazione che conteneva il testo di Albertine disparue con notevoli rimaneggiamenti appartenenti a quell'ultimo anno di vita dello scrittore, che aveva eliminato quasi trecento pagine ma non aveva avuto il tempo di ricostituirne il contenuto. Questa pubblicazione veniva a riproporre il problema dell'incompiuto della Recherche, problema peraltro che si era fatto luce nella coscienza critica solo dal 1954, con l'edizione Pléiade del romanzo proustiano, e che aveva trovato le più varie accoglienze.

2 L'opera di Nathalie Mauriac vuole fare, con la più scrupolosa diligenza e la più ampia documentazione, il punto sull'insieme dei problemi posti dalla presenza di questo testo dattiloscritto. Si tratta della genesi ancora non conosciuta del romanzo, che sconvolge la ricostruzione postuma e la tradizione editoriale. Si tratta anche della storia di Proust e del suo lavoro nel 1922 attorno a Sodome et Gomorrhe III ed a Sodome et Gomorrhe IV, cioè circa mille pagine dattiloscritte. Si tratta di una ricostruzione postuma che la morte repentina dell'autore ha reso necessaria per i primi editori. Si tratta infine della storia dell'edizione postuma di Albertine disparue, così come è stata conosciuta per oltre mezzo secolo, e dell'interrogazione ormai fondamentale: come pubblicare questa parte del romanzo e l'insieme dei testi postumi di Proust? 
3 In successivi capitoli l'A. disegna l'interesse letterario del testo studiato e delle varianti del 1922 e postula le condizioni di una critica dell'incompiuto proustiano. Ma, in realtà, questo libro attento e maturo è molto più ricco, di contenuti e di apparati, di quanto una breve segnalazione possa dire: solo una lettura attenta pagina dopo pagina può farne giustizia. 